\title{
As cenas musicais como moldura analítica do lazer noturno: homossexualidades masculinas em perspectiva
}

\author{
Diego Eugênio Roquette Godoy Almeida ${ }^{a}$ (D), Rosário Silvana Genta Lugli

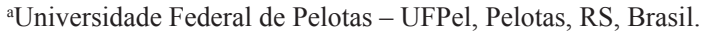

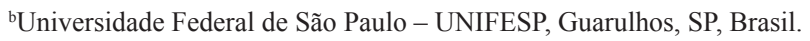

\begin{abstract}
Resumo: Pensar nos territórios sonoros da cena musical parece ser uma perspectiva interessante para a terapia ocupacional, no que se refere ao "fazer gênero" entre jovens homossexuais metropolitanos. O objetivo deste artigo é apresentar o exercício teórico-metodológico através do qual as cenas musicais surgiram como perspectiva analítica do lazer noturno metropolitano marcado pelas homossexualidades masculinas. Em um segundo momento, espera-se apontar contribuições dos estudos de gênero para o campo da terapia ocupacional, com base nos achados empíricos. A imersão etnográfica se deu desde janeiro de 2016 a julho de 2017, nas regiões da "Augusta" e "Barra Funda", ambas na cidade de São Paulo-SP. A caminhada como técnica oriunda da antropologia urbana serviu como um "flerte inicial" com o campo de pesquisa em fase de definição, através do qual foram traçadas as primeiras linhas classificatórias advindas do confronto de conceitos pré-existentes e os dados empíricos. Conclui-se que a cena musical colocou-se como rentável recorte do lazer noturno em interface com as questões de gênero, ajudando inclusive a repensar fundamentos epistemológicos da atividade em terapia ocupacional.
\end{abstract}

Palavras-chave: Terapia Ocupacional, Identidade de Gênero, Homossexualidade, Atividades de Lazer.

\section{The musical scenes as analytical framework of nighttime leisure: male homosexualities in perspective}

\begin{abstract}
The music scene as sound territories seems interesting perspective for Occupational Therapy in regard to "making gender" among young metropolitan homosexuals. The aim of this work is to present the theoretical-methodological exercise of delimitation of the investigative object of a doctoral research, through which the musical scenes emerged as an analytical perspective of the nocturnal metropolitan leisure marked by masculine homosexuality. In a second moment it is hoped to point out contributions of the Gender Studies for the field of Occupational Therapy based in empirical dates. The immersion in the field happened since January until July 2017 at "Augusta" and "Barra Funda" region. "Walking" was used as a technique from Urban Anthropology. It works as initial contact with the research field in which the time is distinct from ordinary walking. At this moment the preliminary classificatory lines arising from the confrontation of preexisting theoretical contents and the empirical data. As conclusion, the musical scene has worked a profitable cut of nighttime leisure in interface with gender issues, even helping to think epistemological fundamentals of the activity in Occupational Therapy.
\end{abstract}

Keywords: Occupational Therapy, Gender Identity, Homosexuality, Leisure Activities. 


\section{Introdução}

O presente trabalho segue a esteira dos estudos contemporâneos sobre sexualidade/gênero em diálogo com os chamados Estudos Culturais e traz resultados parciais de uma pesquisa de doutorado cujo objetivo foi investigar a produçáo de homossexualidades sob o viés geracional, a partir da etnografia de cinco festas que compóem a cena pop LGBT da cidade São Paulo/SP. Especificamente, neste artigo, será apresentado o processo teórico-metodológico inicial de construção do objeto de investigação, bem como alguns conceitos elaborados empiricamente a respeito da sociabilidade, no lazer noturno de jovens homossexuais masculinos. Espera-se, como desdobramento, apontar aproximações entre os estudos culturais, estudos de gênero e a terapia ocupacional, sugerindo conceitos úteis à compreensáo do cotidiano juvenil em espaços citadinos.

Quanto à relevância, é preciso pontuar a escassez de produçóes científicas em terapia ocupacional que relacionem as dimensôes do cotidiano às expressôes de gênero e sexualidade, em especial a dimensão do lazer. Ainda assim, pesquisas recentes sinalizam avanços na área, no sentido de apresentarem matrizes analíticas cada vez mais diversificadas e robustas, decorrentes de aproximaçóes oportunas com as teorias pós-estruturalistas e socioculturais, na compreensão das formaçóes subjetivas, do cotidiano vulnerável, da "cidadania LGBT", ressaltando que os/as autores/as se mostram atentos/as às agendas dos movimentos sociais, deflagrando situaçôes precárias pertinentes à atuação da terapia ocupacional (MONZELI; LOPES, 2013; MELO, 2016; MURASAKI; GALHEIGO, 2016; LEITE JÚNIOR; LOPES, 2017).

O lazer é considerado uma das dimensões contemporâneas centrais na compreensão das subjetividades juvenis, especialmente no que diz respeito às homossexualidades em território metropolitano (PARKER, 2002; FACCHINI; FRANÇA; BRAZ, 2014). Stuart Hall (2015), acerca disso, fala sobre a "crise das identidades" no capitalismo tardio, cujas tradicionais âncoras de identificação, entre as quais a de classe social e sexo/gênero, vão tendo seus limites tensionados. Se a anatomia corporal já não oferece tantas certezas acerca de si, se essa mesma subjetividade não pode ser reduzida ao modo de produçáo econômico qual imagem especular, se o trabalho formal já não é o único caminho para sobrevivência e realizaçáo pessoal, resta inquirir sobre a produção subjetiva a partir destes territórios heterotópicos.

Estudos antropológicos já avançaram na compreensão de como se conjugam mercado de lazer, sexualidade e sociabilidade (FACCHINI; FRANÇA; BRAZ, 2014), destacando-se, entre estes, os trabalhos da antropóloga Isadora L. França. Em sua dissertação, na qual é feito o mapeamento do mercado de lazer GLS de São Paulo, a autora evidencia as "pontes e cercas" existentes entre os ativistas LGBT e empresários, construídas ao longo da década de 1990, período chamado de "florescimento do mercado GLS”, quando houvera forte tendência a combinar militância política com as atividades de lazer, a fim de dar maior visibilidade ao movimento (FRANÇA, 2006). Surgia, nesta época, um mercado altamente especializado para o público homossexual, incluindo festivais de cinema, editoras, sites e revistas, que se alimentavam do cotidiano dos consumidores e, ao mesmo tempo, forneciam imagens sobre certo "modo de ser homossexual". Com isso, os "atores do mercado" passaram a ser vistos também como articuladores de uma ação política que visava à "autoestima e a afirmação de uma identidade positiva”.

Já em outra pesquisa, França (2012) inquiriu sobre a produção de categorias identitárias relacionadas à homossexualidade masculina, em contexto de segmentação de mercado na cidade de São Paulo, partindo de um recorte de espaços de sociabilidade e consumo. Para isso, foram etnografados três "lugares-chave", chamados assim por serem boates contrastantes entre si em termos socioidentitários, e os achados apontaram para diferentes homossexualidades cujos sentidos situacionais extrapolavam a questáo da orientação sexual devido à intersecção de marcadores de classe social, raça/cor e gênero.

Tal desenho metodológico foi referenciado na abordagem interseccional da feminista indiana Avtar Brah (2006), para quem a importância investigativa está na diferença, isto é, na análise de como as formas específicas de discursos sobre a diferença se constituem, são contestados, reproduzidos e (re)significados, pensando na diferença como experiência, como relação social, como subjetividade e como identidade (BRAH, 2006). Partindo dessa perspectiva, é primordial compreender como as estruturas de classe, raça/cor, gênero e sexualidade se articulam, não podendo ser tratadas como variáveis independentes, "[...] porque a opressão de cada uma está inscrita dentro da outra - é constituída pela outra e é constitutiva dela" (BRAH, 2006, p. 351).

Para além dos operadores de classe, gênero e raça/cor, etnia e geração, a categoria estilo também é usada para compreender como atributos estéticos se transformam em vetores de diferenciação nos espaços de sociabilidade e lazer (VEGA, 2008; FACCHINI, 2008). Neste aspecto, cabe mencionar a contribuição de Regina Facchini (2011), ao explorar a articulação 
entre política e estilo na cena paulistana feminista das "minas do rock". Ela sugere levar em conta os agenciamentos inerentes ao processo de citar e deslocar normas sociais, e que isso pode se dar na composição de um estilo, da aparência, da música, ainda que os efeitos políticos dessa açáo não sejam inteiramente conscientes.

Mais do que responder aos anseios de consumo, o mercado é ativo na produção de subjetividades (FRANÇA, 2012). Cria-se um produto e, agregado a este, um perfil de consumidor que funciona como matriz de identificaçáo baseada em um estilo de vida determinado, suscetível de certos prazeres e novas necessidades-frustraçôes. Neste ponto, torna-se precisa a crítica de Félix Guattari acerca do capitalismo copulador da subjetividade: ele não só explora a força de trabalho "[...] como também manipula em seu proveito as relaçóes de produção, insinuando-se na economia desejante dos explorados" (GUATTARI, 1985, p. 20). Assim, a localização, bem como o tipo de serviço e seu preço, a publicidade, o tratamento dado aos clientes, o perfil dos frequentadores e o gênero musical, vão servindo de códigos territoriais ativos na produçáo de desejos, práticas, identidades, dimensóes da intersubjetividade que extrapolam a questấo do sexo entre dois homens. Por isso, o termo homossexualidade deve sempre vir acompanhado de diversas ressalvas, tendo em vista a inexistência de uma unidade, comunidade, cultura ou qualquer outro conceito que remeta a semelhança e homogeneidade entre indivíduos (SIMÓES; CARRARA, 2014).

\section{A Construção Peripatética do Objeto ou o Flâneur pela Cidade}

Já no início da década de 1980, Edward MacRae (2005), no seu artigo "Em Defesa do Gueto", escrevera sobre a "explosão do comportamento homossexual" nos espaços públicos e comerciais, resultando em crescente visibilidade. Neste texto, ele resgata fatos históricos, como os primeiros shows de travestis nos anos 1950, nas boates "exóticas", repletas de artistas e intelectuais; a produção musical da Tropicália, "Dzi e os Croquetes" e a androginia dos "Secos e Molhados" nos anos 1960 e 1970, Ângela Rô Rô e a criação do jornal "Lampiáo", em 1978, cujo conteúdo "impublicável e ousado" tornou-se marco significante na história da homossexualidade no país, e sem deixar de citar, é claro, o "Grupo Somos", primeiro coletivo político de afirmação homossexual do país.

O avanço do "gueto gay", contudo, foi afetado diretamente nos anos 1990 pela epidemia da AIDS, mudando drasticamente a base sobre a qual a opiniáo pública falava sobre sexualidade e, de maneira dúbia, os efeitos sociais não só contribuíram para que as homossexualidades fossem estigmatizadas, mas também publicizadas pelos meios de comunicação da época, numa espécie de ampla divulgação de assuntos que até então estavam restritos ao "gueto" ou mesmo aos círculos científicos e às camadas sociais escolarizadas (PARKER, 2002; SIMÔES; FRANÇA, 2005). A disseminação desses conteúdos, inclusive, favoreceu a emergência da "identidade gay", tal qual é representada hoje em dia, com base nos modelos médico-psicológico e igualitário, os quais serão explicados um pouco mais à frente.

Quando MacRae (2005) usou o termo gueto, o autor se referia aos espaços de sociabilidade marcadamente homossexual, "catalizadores dos encontros", e também como uma espécie de lugar onde os sujeitos poderiam exercitar a autoaceitaçáo de forma "protegida" e sem culpa. Nèstor Perlongher (1987), antropólogo argentino que estudou os michês paulistanos, também se apropria do termo, até entáo presente nos estudos etnossociológicos da Escola de Chicago. Ele, porém, aproxima a noção de gueto da definição deleuziana de territorialidade, isto é, espaço nômade localizável, mas não delimitado geograficamente. É que em lugares, como Nova Iorque, Los Angeles e São Francisco, vê-se verdadeira concentração de gays em alguns distritos, podendo-se falar em uma etnia comum devido ao isolamento social nos guetos, que também servem de área residencial e comercial (PERLONGHER, 1987).

De fato, não é possível afirmar a existência de um "gueto gay" paulistano no sentido literal, pois, em muitos lugares chamados GLS pelo mercado, nem sempre existem elementos que indiquem uma identidade coletiva, homogênea e com fixação geográfica. Visto isso, qual unidade analítica seria adequada ao meu propósito de investigar a produção de homossexualidades em lugares de lazer e sociabilidade noturna?

\section{Esclarecimentos sobre as Questões Ético-metodológicas}

Alexandre Paulino Vega (2008), em sua dissertação de mestrado sobre a negociação de estilos no contexto da Rua Augusta e suas imediaçôes, fala sobre as dificuldades enfrentadas ao acessar os frequentadores gays dos bares e boates durante a pesquisa de campo, supostamente pela sua orientação heterossexual. $\mathrm{O}$ pesquisador argumenta com base em circunstâncias em que as pessoas se esquivavam ou tornavam a 
conversa menos espontânea após enxergarem nele alguém que não partilhava dos mesmos códigos. Segundo ele, a diferença entre a sexualidade do entrevistador e do entrevistado implicaria em uma dificuldade de rapport, alterando significativamente o conteúdo das respostas dadas.

Sua interessante reflexão sobre o método, de alguma forma, ofereceu um contraponto à minha aproximação com o campo, já que mesmo na condição de homossexual, nestes mesmos lugares, cheguei a enfrentar desafios semelhantes na abordagem dos interlocutores.

De alguma maneira, coloco em interrogação tais apontamentos, tendo em vista que sempre há o risco de supervalorizar a questão do comportamento sexual em detrimento de muitos outros eixos de diferenciação. Para um pesquisador heterossexual, talvez essa dimensão seja a que se apresente de pronto, mas não para o entrevistado. A festa investigada por Alexandre Vega é descrita por ele mesmo como um ponto de encontro não só para homossexuais, mas também para heterossexuais abertos a novas experiências afetivas.

No meu caso, além da sexualidade, a minha aparência, a ausência de um repertório musical comum, sobretudo minha linguagem pouco afeita às gírias e "memes", me colocavam na condição de estrangeiro, pelo menos no começo do trabalho de campo. Além disso, há sempre o risco de importunar as pessoas em seu momento de lazer, ainda mais com perguntas relacionadas à sexualidade.

Ciente da improdutividade de uma abordagem direta pela desconfiança que esta poderia causar, eu decidi fazer de forma diferente. Era necessária uma participação mais intensa para que as pessoas me reconhecessem e me aceitassem por meio dos mecanismos acionados por eles mesmos, que fazem parte do espaço social chamado de noite. No início, eu só me dedicava à observação dos fenômenos gerais, sem uma abordagem direta. Após algum tempo, decidia se era o momento oportuno para lançar mão do "capital social" conquistado para incentivar a adesáo de alguém à entrevista.

O pertencimento à noite pode ser lido nos termos do capital social de Pierre Bourdieu (1980), por conta da existência de uma rede de "reconhecimentos duráveis" que delimitam a noite como espaço social, além das estratégias mais ou menos conscientes usadas pelos jovens no intuito de angariar recursos por meio desta pertença. A atuação profissional como divulgador, DJ, hostess, performer ou produtor seria um estágio mais avançado, no qual o frequentador, após decifrar as "regras do jogo", transforma-se em uma pessoa da noite, "guardião" dos limites deste espaço, com vistas a transformar seu capital social em capital econômico.

Sobre as estratégias de participação no contexto investigado, foi essencial não enxergar essas práticas como excessivamente exóticas. Como salientou Vega (2008), a estranheza permite a apreensão crítica dos fenômenos e a tradição antropológica prepara o etnógrafo para as possíveis barreiras de cunho étnico, econômico e social. Contudo, neste caso, o próprio campo explicitou as regras de participação das quais fiz uso, evidentemente correndo o risco de uma aproximação táo grande que "borrasse" minha percepçáo. Enfim, foi o caminho que encontrei e assumi o risco.

Coube a mim, revelar as intenções acadêmicas quando identificava potenciais interlocutores para as entrevistas, formalizadas no convite, nas informaçóes sobre a pesquisa e no Termo de Consentimento Livre e Esclarecido².

Não relato, nestas páginas, o processo das entrevistas, senão os aspectos preliminares da construção metodológica; todavia, ressalto a advertência de Pierre Bourdieu (2012) acerca dos cuidados éticos pertinentes às entrevistas. Para o sociólogo francês, pensar o método é, sobretudo, uma postura de reflexibilidade diante de seu campo. A violência situa-se como fenômeno inerente à relaçáo de pesquisa e deve ser "conhecida e controlada", pois diferentemente das agressôes físicas com as quais estamos acostumados em nosso dia a dia, esta violência acontece de forma muito sutil e é diretamente proporcional à dissimetria social entre o pesquisador e o pesquisado. A exigência ética, entre outros modos, situa-se em como aproveitar desse excedente para instaurar uma relação de escuta ativa e metódica, compreensiva, reduzindo censuras, precipitaçôes analíticas, criando 'ares de naturalidade', nesta troca.

$\mathrm{Na}$ esperança de dar contorno àquelas primeiras impressôes um tanto quanto caóticas, oriundas do contato com as festas, comecei a estudar Antropologia Urbana e etnografias sobre o lazer na cidade de São Paulo. Nestes estudos, encontrei referências sobre as caminhadas, por meio das quais eu poderia delimitar meu campo, elegendo o que entraria ou não no escopo de observações.

Caminharé uma técnica oriunda da Antropologia Urbana proposta por José Guilherme Magnani (2005). Neste instante inicial, o tempo é distinto do andar ordinário, quando se considera o ritmo apressado de uma metrópole, mas também não se trata do ritmo distraído e descompromissado, pois 
há um objetivo. Informações fundamentais são coletadas, como natureza do espaço, fluxo de carros, pedestres, esquinas, localização de comércios, etc., a partir das quais o olhar do pesquisador já começa a traçar linhas classificatórias. Para mim, funcionou como um "flerte intelectual" com meu objeto de pesquisa. Fui tentando tocar as superfícies, saber o que estaria dentro ou fora dessa minha relaçáo relativamente breve de quatro anos de pesquisa, saber o nome e a textura das coisas, para, só entấo, criar uma sistemática de observaçôes.

Antecipo que não foi fácil sair da impressão caótica do primeiro instante. Na verdade, conseguir certo distanciamento necessário à observação foi um desafio constante em todas as idas a campo, posto o excesso de estímulos que teimavam em tirar o foco da minha atenção, provocando certa "cegueira", ora pelo encantamento, ora pela sensação de intimidade com os acontecimentos. Diversas vezes, tive a sensação de que as coisas se repetiam óbvias e sem importância, o que me angustiava, sem dúvida, e colocava frequentemente em xeque minha competência etnográfica. Contudo, nestes instantes, era essencial o aporte teórico, visto que a caminhada consiste em uma técnica que só faz sentido dentro do quadro mais amplo da etnografia.

Seguindo as advertências de MacRae (2015), passei algum tempo frequentando festas "informalmente", a fim de ter maior consciência do material e das outras técnicas com que iria trabalhar. Os acontecimentos eram registrados no bloco de notas do celular, que fazia as vezes do tradicional caderno de campo, e, posteriormente, transcritos, ao modo de uma descrição densa. Como as categorias de análise não são dadas a priori, fez-se necessário destacá-las da matriz cotidiana complexa e imprevisível, para, em seguida, fornecer um vocabulário no qual pudesse ser expresso o que o ato simbólico teria a dizer sobre ele mesmo (GEERTZ, 2008).

Adiante, explicitarei como cheguei à ideia de cena musical e seu potencial heurístico na pesquisa sobre lazer noturno e homossexualidades.

\section{A Cena Pop LGB'T Paulistana}

A adoção da cena $^{3}$ como delimitaçáo do objeto de estudo surgiu do contato com nativos da noite, já como produto empírico das caminhadas. LGBT refere-se às categorias identitárias "Lésbicas, Gays, Bissexuais, Travestis e Transexuais" e GLS, por sua vez, é a sigla mercadológica para designar "Gays, Lésbicas e Simpatizantes", introduzida no Brasil nos anos 1990 pelo festival de cinema Mix Brasil
(TREVISAN, 2002). Intencionalmente, usarei em todo o corpo do texto a sigla GLS para me referir à dimensão mercadológica e LGBT quando a ideia for enfatizar a produçáo cultural ou a afirmaçáo identitária da cena musical pesquisada.

Ainda que sejam imprecisas e um tanto quanto vagas, as expressóes cena drag, cena pop, cena indie e cena $L G B T$ são largamente usadas para traçar fronteiras, tomando como referências o consumo musical e as identificações coletivas. Daí a importância do conceito, pois, além de dar textura e pulso à cidade, as cenas também dão contorno, criam proximidades, distanciamentos e inauguram rotas de identificação.

Will Straw, que compôs o círculo de debates em defesa da cidadania noturna em São Paulo, esclarece:

As cenas são unidades náo oficiais da vida urbana diferentemente dos bairros ou dos distritos. Uma cena adquire visibilidade quando alguma espécie de atividade cultural se torna parte da sociabilidade pública, e quando essa mesma sociabilidade serve para a contínua produção e consumo de cultura. Nas cenas, a atividade cultural gera a sociabilidade como uma espécie de excesso afetivo que se torna então parte da efervescência observável da vida urbana. Ao mesmo tempo, a interação social fomenta o entusiasmo, as trocas e as redes através das quais a cultura é feita e disseminada (COLABORATÓRIO, 2014, p.105).

Foi nos anos 1990 que a cena começou a ser usada como modelo analítico, em rejeição às outras categorias tradicionalmente usadas, como subcultura e comunidade (BENNETT, 2004). Subcultura foi um termo introduzido pela Escola de Chicago, na abordagem de temas relativos ao desvio e ao crime. Já nos anos 1970, o termo foi incorporado aos Estudos Culturais britânicos para compreender a formação de identidades juvenis subalternas, como os teddyboys, mods e punks, no período pós-guerra. $\mathrm{Na}$ segunda edição de um periódico de divulgação do Centre of Contemporary Cultural Studies (CCCS), Phil Cohen rompe com as noçôes psicopatológicas e criminalizantes no campo das investigaçóes e, pela primeira vez, compreende as subculturas juvenis como formaçóes sociais razoáveis e coerentes. Segundo Cohen, os mods, skinheads e crombies tentavam resolver simbolicamente as contradiçóes sociais relacionadas com a erosão de antigos espaços comunitários, as transformações na organização do trabalho e a fragmentação da família tradicional (FREIRE FILHO, 2007).

Pouco tempo depois, referenciados por Gramsci, inúmeros estudiosos combateram a ideia 
mercadológica de uma juventude emergente após a II Guerra Mundial, que existia qual bloco popular, homogeneizados pelo consumo. Eles propunham, em vez disso, retratos cautelosos que considerassem as condiçôes socioculturais estruturantes sobre as quais erigiam as distintas subculturas juvenis, sobretudo a divisão de trabalho e as relaçôes de produção, sem negligenciar as especificidades geracionais e de conteúdo. Esses estudos ressaltavam o poder das atividades de lazer-subcultural marcadas pelo dissenso, ainda que estas fossem instáveis, circunscritas e não revolucionárias (FREIRE FILHO, 2007, p. 32). Além disso, reconheciam que as soluções não eram apenas "ideológicas", mas a concretude estava na negociação dos tempos e lugares citadinos ocupados para diversão, circulação e manifestação.

Naquela época, a chave de interpretação era a estilização, isto é, a articulação dos objetos usados pelas subculturas e os valores do grupo, produzindo uma identidade coletiva. As motocicletas para os rockers, os alfinetes e correntes para os punks, os ternos de corte refinado para os teddy boys são alguns exemplos da homologia entre os apetrechos estilísticos e a subcultura. Dick Hebdge (1979), na esteira de Stuart Hall e Tony Jefferson (1976), em Resistence Throught Rituals, aproveitou o cruzamento teórico de homologia e bricolagem, tomado de Lévi-Strauss, para dizer do caráter transgressor do estilo, em vez de simples expressáo. O primeiro termo designa a relação entre os objetos estilizados e os valores do grupo, já bricolagem é a "arte concreta" de transgredir o uso habitual de objetos, transferindo-os para outros contextos, numa espécie de "guerra ideológica".

Com o passar do tempo, subcultura foi se desvinculando da problemática que justificou seu surgimento: a resistência de parte de jovens provenientes da classe trabalhadora britânica em relação às condições estruturais (BENNETT, 2004). Neste aspecto, várias críticas alertam sobre o possível uso problemático do conceito, seja por trazer indevidamente a estrutura de classes no cerne das formaçôes identitárias, sejam pelas características de coesão grupal e homogeneidade de estilo nem sempre observáveis.

Quanto à categoria comunidade, Andy Bennett (2004) qualifica-a como uma maneira romântica de se referir à conexão entre pessoas que convertem a música em uma espécie de "modo de vida" e fonte de representaçốes. Como exemplo de aplicação de tal conceito, a autora cita o movimento hippie na década de 1960, no qual se enxergavam o compromisso com as críticas sociais por meio do rock e a "conexão emocional" entre os músicos do indie e suas audiências.
Novamente, as supostas homogeneidade e coesão respaldavam o uso do conceito.

A perspectiva das cenas nasce para o mundo acadêmico, pelo menos de uma forma mais elaborada, com o ensaio do canadense Will Straw (1991) Systems of Articulation, Logics of Change, numa tentativa de dar ao constructo maior robustez teórica. Para ele, as cenas musicais são territórios sonoros destinados ao consumo da música popular, com fronteiras difusas e sempre negociadas (STRAW, 2004). Ao pensar nesta definição, o autor estava considerando as fertilizações cruzadas (crossfertilization) e fragmentaçóes daqueles "estilos clássicos" de décadas anteriores. Nas cenas do rock alternativo e dance music, por exemplo, já não existiam subculturas coesas como nos anos anteriores, senão estilos derivados que se afetavam mutuamente a partir de influências locais e de outros países. $\mathrm{Na}$ era "pós-subcultural", sua preocupação era romper com as noçōes de autenticidade e nacionalismo tão caras, à época, nos Estudos Culturais, e assim avançar na compreensão das alianças produzidas pela circulação dentro da cultura musical. Nesse ponto, cabe ressaltar que a dinâmica de uma cena náo é o resultado puro da sociabilidade, mas, também, fruto das tentativas abrangentes das indústrias fonográficas de tornar a música mais lucrativa, ao segmentá-la.

Depreende-se que a potência heurística do conceito advém da possibilidade de uma cartografia heterogênea nos seus elementos unificadores, desafiando o rígido modelo subcultural e quaisquer análises "localistas". Acredito, contudo, ser necessária breve revisão do conceito de Will Straw no que concerne ao reducionismo da sociabilidade na cena às alianças de solidariedade, visão esta muito semelhante aos vínculos transitórios e emocionais das neotribos de Maffesoli (2004). Durante as caminhadas, por exemplo, notei desigualdades de oportunidades profissionais entre $D J$ 's associadas às diferenças de classe e raça/cor, as quais vieram a se confirmar nos momentos futuros, quando me dediquei às entrevistas com algumas pessoas da noite $e^{4}$. Em outras palavras, não havia só alianças em torno da música, senão vetores que demarcavam aproximaçóes e distanciamentos.

A partir disso, apostei na abordagem interseccional de Avtar Brah (2006), agregando valor ao constructo de Will Straw, dadas as possibilidades territoriais de não só existirem relaçôes de amizade e partilha, mas também hierarquias, disputas e desigualdades que se somavam, criando complexo panorama de investigação.

A cena que compôs meu campo abrangeu cinco festas que aconteciam em estabelecimentos diferentes, sendo três destas na Região da Augusta e duas na 
Barra Funda: Hangover, Ratchet, Bug, The People e Plástika. Estes mesmos locais sediavam outras festas, que integravam cenas musicais diversas em razáo dos estilos musicais e das características dos frequentadores. As festas ficavam sob reponsabilidade direta dos produtores/DJ's, colocando a figura dos empresários donos dos estabelecimentos em segundo plano.

Evidente que a cena pop $L G B T$ paulistana extrapola os limites aqui indicados. Seria impossível um projeto individual que pretendesse mapeá-la em sua totalidade, com precisão geográfica. Diante desse desafio de refinamento, algumas características foram elencadas a fim de discriminar a cena compreendida por esta pesquisa:

Idade: a faixa etária da maior parte dos consumidores varia entre 18 a 24 anos, constituindo um público preponderantemente jovem;

Rede Social: a cena é uma espécie de desdobramento da rede social formada por um grupo de profissionais produtores e divulgadores de festas, DJ's e hostess, também chamados de pessoas da noite. A relaçâo estabelecida entre eles, por meio de parcerias profissionais ou mesmo relaçóes de amizade, cria "certa aparência de continuidade" entre os lugares, fazendo com que o público em geral encontre características semelhantes nas diferentes festas;

Gênero/sexo: público preponderante do sexo masculino, autorreferenciados como gays. Isso não quer dizer que mulheres não frequentem o espaço, porém acontece em menor número. Há também presença constante e valorizada de mulheres transgênero e pessoas que se identificam como náo binárias;

Música: o pop acaba sendo um termo inespecífico para falar dos gêneros musicais nestes lugares, os quais variam das brasilidades (Vanessa da Matta, Pitty, CPM-22, Bonde do Tigrão, Rouge), passando pelo eletrônico, funk, música latina e pop (Madonna, Beyoncè, Rihanna, Lady Gaga, Justin Bieber, etc.). Alguns sucessos nacionais do momento, de natureza mais independente, divulgados na internet, também costumam fazer bastante sucesso, como no caso da Inês Brasil, Mc Linn da Quebrada e das drag queens Lia Clark, Pablo Vittar e Glória Groove.

\section{Gênero e Homossexualidades Masculinas}

A dimensão do gênero foi a mais importante no que concerne à apreensão da cena pop LGBT. Ainda que tal operador de diferença social não possa ser lido de forma independente dos outros, aqui será apresentada breve síntese de alguns estudos clássicos que ajudaram nessa aproximação inicial.

Contra qualquer risco de essencializar as identidades de gênero, os estudos de Peter Fry e Edward MacRae (FRY; MACRAE, 1985) constatam que não há uma homossexualidade universal, determinada pelos fatores genéticos ou psicológicos, senão discursos e práticas forjadas historicamente no íntimo das sociedades.

Tal consideração é muito pertinente, já que é corriqueiro encontrar, nos discursos religiosos e científicos, a ideia de identidade como ontologia, ou seja, algo que se é, anterior às relaçôes, substância radicada no interior do psiquismo ou no código genético. Nesse mesmo sentido, Michel Foucault (2014) afirma que a sexualidade é um "dispositivo histórico". Isso significa que ela é uma produçấo social de "verdades" sobre o sexo e seus prazeres com a função de regular, normatizar, incitar discursos, conhecimentos e resistências. Muito mais que recalcar ou proibir, no mundo moderno, as instituiçôes agem no sentido de produzir formas consideradas adequadas de sexualidade. Deste modo, a conjugalidade, a heterossexualidade e a monogamia ganham status de legitimidade e visibilidade no regime histórico atual, tratando outras formas de prazer como periféricas, anormais e desviantes (MISKOLCI, 2015).

Heteronormatividade é um dos termos essenciais ao problema que se coloca: diz respeito à matriz histórico-cultural através da qual dividimos o mundo em dois grandes grupos complementares, homens e mulheres, em função das características genitais, acreditando que todos os desejos e prazeres são produçóes biológicas, naturais, universais e que servem eminentemente à reprodução da espécie (PRECIADO, 2014). Com efeito, os corpos que não se "encaixam" nos padróes rígidos e limitados de masculinidade e feminilidade ficam expostos às mais diversas formas de violência. Nancy Fraser (2017), a esse respeito, fala do "falso reconhecimento" atribuído à população LGBT, já que cotidianamente lhe é negada a condição de parceiro/a integral nas trocas sociais, isto é, são indivíduos privados de escolarização, cuidados básicos, profissionalização e existência pública (FRASER, 2017).

Ciente destas linhas de opressão, torna-se compreensível a precariedade a que são relegados os sujeitos ininteligíveis à gramática heteronormativa. O "armário" representa, para muitos, o dispositivo que coloca sob ameaça o ato de tornar pública qualquer expressão sexual dissidente (SEDGWICK, 2007), daí mais um elemento para se pensar a relevância dos territórios de lazer noturno. 
Ainda sobre a construção cultural da sexualidade, Fry (1982) propóe três sistemas taxonômicos de entendimento sobre homossexualidade que estariam diferencialmente disseminados no país, com base em etnografias realizadas em terreiros de candomblé da periferia de Belém-PA, nos anos 1970: 1) Modelo hierárquico ou tradicional, ancorado no binarismo masculinidade/atividade sexual $\times$ feminilidade/passividade sexual; 2) Modelo médico-psicológico, a partir do qual "o sexo biológico" e "papel sexual" se dissociam paulatinamente, de modo que a prática sexual entre pessoas do mesmo sexo definiria a "condição anormal do homossexualismo", sem se ater a posição "ativa" ou "passiva" durante o coito; 3) Modelo igualitário: deriva do modelo médico, pois se sustenta na oposição homo/heterossexualidade; contudo, vem em contestação à patologização da homossexualidade.

$\mathrm{Na}$ sua avaliação, o modelo tradicional teria mais força nos estratos populares, de forma que o homem seria o macho sexualmente ativo e viril, náo importando se ele também se relacionasse com pessoas do mesmo sexo. Caso essa mesma pessoa do sexo masculino fosse "penetrado" ou "tivesse trejeitos", automaticamente a pessoa passaria a integrar o universo feminino - "uma mulher no corpo de homem”. Neste sistema de interpretação, só haveria duas opçôes, ou é masculino ou é feminino, sendo que a segunda está submetida à primeira, por isso a hierarquia. A homossexualidade, nesses termos, não seria uma categoria independentemente da prática sexual. As perguntas presentes em tais contextos seriam mais ou menos estas: Quem "come" e quem "dá"? Quem éa "mulherzinha" ou o "macho" da relação?

Coexistindo com o modelo tradicional, Fry ateve-se ao termo oriundo das classes médias das cidades de São Paulo e Rio de Janeiro, para nomear os homossexuais daquela época: o "entendido" e a "entendida". Os entendidos exemplificavam o "modelo igualitário", no qual o homossexual experimentaria maior liberdade quanto ao desempenho da atividade sexual (passivo/ativo) e do gênero (feminino/masculino) (FRY, 1982; GUIMARÃES, 2004). Os homens heterossexuais, desse modo, eram os que se relacionavam com o sexo oposto, ao passo que entendido (seja ele efeminado ou masculinizado, ativo ou passivo) compreendia os que se relacionavam sexualmente com alguém do mesmo sexo.

Sobre a independência entre identidade de gênero e prática sexual, é importante lembrar a categoria HSH (Homens que fazem Sexo com Homens) usada pelo Programa Brasileiro de DST e AIDS do Ministério da Saúde, a fim de incluir, nas açóes de vigilância epidemiológica e prevenção, os homens que se relacionam afetivo-sexualmente com outros homens, esporadicamente ou não, mas que não se reconhecem como homossexuais, gays ou outra categoria semelhante (BRASIL, 2002).

Embora eu não tenha encontrado nenhum entendido no campo paulistano, a recapitulação cumpre efeito de uma compressão histórica das homossexualidades no Brasil, tendo em vista as mudanças geracionais náo lineares observadas ao longo das últimas quatro décadas relativas à fragilização do modelo hierárquico (FACCHINI, 2004). Nos dias atuais, outros elementos agem na sobredeterminação subjetiva das identidades de gênero, principalmente em se tratando de uma cena musical atravessada por artefatos midiáticos globais.

Richard Miskolci (2015) explica que, na passagem do milênio, o ecossistema midiático passou a ofertar uma gama de novas representaçóes sobre gays e lésbicas, que funcionariam como matrizes sobre as quais são gestadas as subjetividades. Vale lembrar que a indústria $p o p$ está repleta delas, sem falar na circulação semiótica de natureza independente pela internet.

É como se as homossexualidades passassem a ser reconhecidas como uma espécie de estilo de vida vinculado às novas formas de comunicação e demandas políticas de apagamento das suas diferenças em relação às heterossexualidades (MISKOLCI, 2015, p. 66).

O mercado GLS e as políticas estatais voltadas para o seguimento LGBT seriam dois exemplos desses dispositivos que atuam no sentido de criar semelhanças de desejo, necessidade e prazer entre grupos (FACCHINI, 2004; MISKOLCI, 2015).

\section{Gênero e Terapia Ocupacional}

As primeiras impressóes sobre o campo respaldadas pela literatura corroboram a tese de que a homossexualidade não é uma questão individual, vocação e muito menos "coisa de adolescente". Gênero é uma construção histórica, um conjunto de atos - não só sexuais - repetidos no interior de uma estrutura reguladora altamente rígida, ganhando aparência de "natural de ser" (BUTLER, 2003). Todas as experiências sociais são gendrificadas, ou seja, ao usar o banheiro, escolher o tipo de carro, assinar um documento, ao ganhar um nome, escolher uma roupa, ao consumir um estilo musical, beber um drink, dançar, frequentar uma boate, fazer um corte de cabelo, tudo está imerso em uma trama discursiva sobre diferenças de gênero, sendo que, no 
regime heteronormativo, somente duas possibilidades se colocam: masculino ou feminino.

Visto desta forma, não há como exagerar nesta fluidez e dizer que ora sou mulher, ora sou homem, não é isso. A insistente e demorada interpelação social faz com que as pessoas tenham que "responder em ato" quem elas são, recorrendo às representaçóes socialmente disponíveis sobre "ser" homem, mulher, criando um relato de si que performa a identidade, ou seja, faz surgir aquilo que só se pretendia descrever.

É assim que sentenças como "você é menina”, "gays têm bom gosto", "homens não rebolam", na verdade são atos performativos, já que fazem parte de uma ampla rede de atos linguísticos capazes de criar identidades, a depender da incessante repetiçáo. A pessoa interpelada tem a impressão de que ela realmente é algo, forçando coerência e rejeitando experiências capazes de colocar em xeque essa identidade performada. Nisso, consiste a materialidade da performatividade: a aparência de identidade que formata (mas com falhas) os gostos, desejos e práticas, criam equipamentos, leis, políticas com base em uma ficção identitária.

Mas, como haveria de se supor, os sujeitos não estáo totalmente fadados a performar modelos tradicionais de gênero. $O$ processo de citacionalidade também é importante ao lado da performatividade. Segundo Judith Butler (2003), a mesma repetibilidade que garante a eficácia dos atos performativos que reforçam as identidades tradicionais pode significar também a possibilidade de interrupção das citações de modelos hegemônicas. É através da interrupção da "paródia de gêneros", do processo de "recorte e cola", que ocorre a emergência de novas identidades.

O conceito de performatividade vem sendo refinado em "Notes Toward a Performative Theory of Assembly", obra mais recente de Butler (2015). Ela aprimora sua teoria, detendo-se com profundidade na dimensáo pública da aparição das identidades. Ela diz que performatividade descreve tanto os processos de "ser" quanto às condiçôes mais ou menos precárias de ação que marcam tais contextos, inclusive tratando das alianças existentes nas assembleias. Este último conceito diz respeito à ocupação de espaços por corpos movidos por questões singulares e às transformações materiais produzidas nestes encontros.

Para além dos "atos de fala" tão bem abordados pela Judith Butler, Karen Barad, Paul B. Preciado e outras feministas pós-humanistas questionam a soberania da linguagem, legado da psicanálise e da semiótica, cujas colocaçóes atribuiriam excessivo poder à linguagem em detrimento da materialidade, deixando escapar a dimensão corporal (BARAD,
2003). Ainda que se reconheça a produção de corpos a partir de tecnologias discursivas, alega Preciado (2014) que, nas últimas décadas, seria antiquada qualquer abordagem em torno da estética dos gêneros que não levasse em conta as tecnologias de gênero (biotecnologias, cirurgias, hormonioterapias) e as tecnologias da representação (fotografia, cinema, televisão, cibernética).

A despeito das divergências, tanto na ótica discursiva quanto na "neomaterialista", há o consenso de que o gênero é uma ficção política criada em quaisquer atividades cotidianas, tanto pela força das representaçóes quanto pelo contato com as tecnologias que funcionam quais próteses subjetivas. Em outras palavras, o poder já não é só disciplinar, ele também é consumido, aplicado, assistido, mastigado, vestido e tomado em cápsulas (PRECIADO, 2014).

A partir deste ponto de vista, atividade ganharia outro estatuto à luz de fenômenos e desafios operantes no contemporâneo. Seria possível entender a atividade como performance de gênero? Em caso positivo, o que as teorias que fundamentam a atividade em terapia ocupacional têm a dizer sobre o "fazer gênero" como acontecimento público, coletivo, relacional, deflagrador de condições precárias? O que o "fazer gênero" tem a ver com a violência, a privaçáo de direitos comuns e a injustiça na distribuição de recursos e reconhecimentos? Com certeza, a terapia ocupacional teria muito a contribuir, desde que se compreendesse a dimensão eminentemente sociopolítica da atividade.

Monzeli e Lopes (2013), em estudo de revisão de periódicos de terapia ocupacional, apontam a ausência de pesquisas na área que compreendam a sexualidade como expressão subjetiva, política e coletiva, indo além da intervençáo clínica. Melo (2016), neste mesmo sentido, problematiza como a estruturação da vida cotidiana nas bases heretonormativas pode implicar em panoramas muito restritos e excludentes, como no caso da "vivência trans", na maternidade, na adoção, na empregabilidade.

As bases epistemológicas da terapia ocupacional social têm fornecido respaldo diferenciado para quem atua na área da sexualidade/gênero, incluindo, em seu domínio de análise, a cidadania, o território e a rede social de suporte (MELO, 2016). Ademais, os estudos sobre cotidiano mostram-se promissores no sentido de romper com o pensamento funcionalista $\mathrm{e}$ positivista, que alimentam a ideia de ambiente como exterioridade, de um sujeito racional e passível de "adaptação" à sociedade. 
Falar de cotidiano em terapia ocupacional representa significativa virada epistemológica, conforme argumenta Sandra Galheigo (2003). O aspecto inovador do conceito vincula-se à perspectiva crítica, caracterizada pela retomada da relação Sujeito-História. Neste viés, notam-se preciosas contribuiçôes de intelectuais, como Georg Lukács, Agnes Heller, Gilberto de Melo Kujawski, Henri Lefebvre e Michel de Certeau, para a compreensão das atividades humanas: estas unidades do cotidiano imersas no tecido político-cultural. É possível constatar a relação entre o particular e o genérico, a força das estruturas de classe e táticas usadas nos afazeres mais banais da vida.

Visando à atuação do terapeuta ocupacional no campo do gênero/sexualidade, busco somar ao debate o pensamento pós-estruturalista e o "olhar de perto e de dentro" dos estudos antropológicos. No caso da cena investigada, não há um "sujeito-homossexual" que vai para cena pop fazer coisas. A própria subjetividade com aparência de um núcleo identitário é produto das relaçóes, das atividades, dos discursos. Um sujeito que não existe nem antes e nem acima da experiência.

\section{Considerações Finais}

A escolha da cena pop como delimitação teórico-metodológica do lazer noturno pareceu bastante coerente no que tange à compreensáo das homossexualidades. Primeiramente, por se tratar de um termo rotineiramente usado pelas próprias pessoas da noite, para criar outra geografia da cidade com base no interesse musical e nos mecanismos de diferenciação. Essa escolha também considera a questáo do estilo na produçáo de identidades, entre as quais as de gênero, sem desconsiderar a problemática política da ocupação dos espaços urbanos (Como se quer ocupar a cidade? Quem pode ocupar a cidade? Para que ocupar a cidade?). Outro ponto interessante, em termos metodológicos, seria a possibilidade de impor limites ao campo de investigaçáo levando em conta a interconexão de lugares a partir da sociabilidade 5 e formas de diferenciação. Cabe ressaltar que a cena pop LGBT não existe isoladamente, o que demanda uma leitura relacional das práticas existentes, tanto em relação às outras cenas culturais quanto aos valores sociais mais amplos.

Acredito que o desdobramento de tais discussões contribuirá para o corpus disciplinar que vem deslocando a terapia ocupacional para além do eixo saúde/doença, particularmente a junção entre lazer noturno e expressóes de gênero dissidentes no regime heteronormativo e heterossexista. Quanto à produçáo de gêneros, a atividade coloca-se como eixo analítico ímpar desde que devidamente formulada em suas bases epistemológicas.

\section{Agradecimentos}

O presente trabalho foi realizado com apoio da Coordenação de Aperfeiçoamento de Pessoal de Nível Superior - Brasil (CAPES) - Código de Financiamento 001.

\section{Referências}

BARAD, K. Posthumanist performativity: toward an understanding of how matter comes to matter. Signs: Journal of Women in Culture and Society, Chicago, v. 28, n. 3, p. 801-831, 2003.

BENNETT, A. Consolidating the music scenes perspective. Poetics, Oxford, v. 23, p. 223-234, 2004. http://dx.doi. org/10.1016/j.poetic.2004.05.004

BOURDIEU, P. O capital social: notas provisórias. In: NOGUEIRA, M. A.; CATANI, A. (Org.). Escritos de educação. Petrópolis: Vozes, 1980. p. 65-69.

BOURDIEU, P. Compreender. In: BOURDIEU, P. et al. A miséria do mundolsob direção de Pierre Bourdieu com contribuiçóes de A. ACCARDO et al. Petrópolis: Vozes, 2012. p. 595-611.

BRAH, A. Diferença, diversidade, diferenciação. Cadernos Pagu, Campinas, n. 26, p. 329-376, 2006. http://dx.doi. org/10.1590/S0104-83332006000100014.

BRASIL. Ministério da Saúde. Secretaria de Políticas de Saúde. Guia de Prevenção das DST/Aids e Cidadania para Homossexuais. Brasília: Ministério da Saúde, 2002.

BUTLER, J. Problemas de gênero: feminismo e subversão da identidade. Rio de Janeiro: Editora Civilizaçâo Brasileira, 2003.

BUTLER, J. Notes toward a performative theory of assembly. Cambridge: Harvard University Press, 2015.

COLABORATÓRIO. Grupo Interdisciplinar. Manifesto da noite. São Paulo: Invisíveis Produçóes, 2014.

FACCHINI, R. Movimento homossexual e construção de identidades coletivas em tempos de AIDS. In: UZIEL, A. P.; RIOS, L. F.; PARKER, R. G. (Org.). Construçôes da sexualidade: gênero, identidade e comportamento em tempos de AIDS. Rio de Janeiro: Pallas - Programa em Gênero e Sexualidade IMS/UERJ e ABIA, 2004. p 151-167.

FACCHINI, R. Entre umas e outras: mulheres, (homo) sexualidades e diferenças na cidade de São Paulo. 2008. $321 \mathrm{f}$. Tese (Doutorado em Ciências Sociais) - Universidade Estadual de Campinas, Campinas, 2008.

FACCHINI, R. "Não faz mal pensar que não se está só": estilo, produção cultural e feminismo entre as minas do rock em São Paulo. Cadernos Pagu, Campinas, n. 36, p. 117-153, 2011. http://dx.doi.org/10.1590/S010483332011000100006.

FACCHINI, R.; FRANCA, I. L.; BRAZ, C. Estudos sobre sexualidade, sociabilidade e mercado: olhares antropológicos 
contemporâneos. Cadernos Pagu, Campinas, n. 42, p. 99140, 2014. Disponível em: <http://www.scielo.br/scielo. php? script $=$ sci_arttext\&pid $=$ S01048333201400010009 9\&lng=en\&nrm=iso > . Acesso em: 20 jan. 2018.

FOUCAULT, M. História da sexualidade 3: o cuidado de si. São Paulo: Terra e Paz, 2014.

FRANÇA, I. L. Cercas e pontes: movimento GLBT e mercado GLS na cidade de São Paulo. 2006. 257 f. Dissertação (Mestrado em Antropologia Social) - Universidade de São Paulo, São Paulo, 2006.

FRANÇA, I. L. Consumindo lugares, consumindo nos lugares: homossexualidade, consumo e subjetividades na cidade de São Paulo. Rio de Janeiro: EdUERJ, 2012.

FRASER, N. Heterossexismo, falso reconhecimento e capitalismo: uma resposta à Judith Butler. Idéias, Campinas, v. 8, n. 1, p. 277-294, 2017.

FREIRE FILHO, J. Reinvençôes da resistência juvenil. Os estudos culturais e as micropolíticas do cotidiano. Rio de Janeiro: Maud X, 2007.

FRY, P. Para inglês ver: identidade e política na cultura brasileira. Rio de Janeiro: Zahar, 1982.

FRY, P.; MACRAE, E. O que éhomossexualidade. São Paulo: Brasiliense, 1985.

GALHEIGO, S. M. O cotidiano na terapia ocupacional: cultura, subjetividade e contexto históricosocial. Revista de Terapia Ocupacional da Universidade de São Paulo, São Paulo, v. 14, n. 3, p. 104-109, 2003. Disponível em: <http:// www.revistas.usp.br/rto/article/view/13924/15742>. Acesso em: 5 jul. 2018.

GEERTZ, C. A interpretação das culturas. Rio de Janeiro: LTC, 2008.

GUATTARI, F. Revolução molecular: pulsaçóes políticas do desejo. São Paulo: Editora Brasiliense, 1985.

GUIMARÃES, C. D. O homossexual visto por entendidos. Rio de Janeiro: Editora Garamond, 2004.

HALL, S. A identidade cultural na pós-modernidade. Rio de Janeiro: Lamparina, 2015.

HALL, S.; JEFFERSON, T. Resistence through rituals. Londres: Hutchinson and Co., 1976.

HEBDGE, D. Subculture: the meaning of style. London: Methuen, 1979.

LEITE JÚNIOR, J. D.; LOPES, R. E. Travestilidade, transexualidade e demandas para a formação de terapeutas ocupacionais. Cadernos Brasileiros de Terapia Ocupacional, São Carlos, v. 25, n. 3, p. 481-496, 2017. http://dx.doi. org/10.4322/2526-8910.ctoAO1060.

MACRAE, E. Em defesa do Gueto. In: GREEN, J. N.; TRINDADE, R. Homossexualismo em São Paulo e outros escritos. São Paulo: Editora UNESP, 2005. p. 291-308.

MACRAE, C. Etnografia. In: SOMEKH, B.; LEWIN, C. (Org.). Teoria e métodos de pesquisa social. Petrópolis: Vozes, 2015. p. 69-78.
MAFFESOLI, M. O tempo das tribos. Rio de Janeiro: Forense Universitária, 2004.

MAGNANI, J. G. C. O circuito dos Jovens Urbanos. Tempo Social - Revista de Sociologia da USP, São Paulo, v. 17, n. 2, p. 173-205, 2005. Disponível em: <http:// www.scielo.br/scielo.php?script =sci_arttext\&pid=S010320702005000200008\&lng=en \&nrm=iso >. Acesso em: 31 jan. 2018.

MAGNANI, J. G. C. Da periferia ao centro. Trajetórias de pesquisas em Antropologia Urbana. São Paulo: Editora Terceiro Nome, 2012.

MELO, K. M. M. Terapia Ocupacional Social, pessoas trans e Teoria Queer: (re)pensando concepções normativas baseadas no gênero e na sexualidade. Cadernos de Terapia Ocupacional da UFSCar, São Carlos, v. 24, n. 1, p. 215-223, 2016. http://dx.doi.org/10.4322/0104-4931.ctoARF0645.

MISKOLCI, R. "Discreto e fora do meio": notas sobre a visibilidade sexual contemporânea. Cadernos Pagu, Campinas, v. 44, p. 61-90, 2015. Disponível em: <http:// www.scielo.br/scielo.php?script=sci_arttext $\&$ pid $=$ S0104$83332015000100061 \& \operatorname{lng}=$ en $\& \mathrm{nrm}=$ iso $>$. Acesso em: 31 jan. 2018.

MONZELI, G.; LOPES, R. E. Terapia ocupacional e sexualidade: uma revisão nos periódicos nacionais e internacionais da área. Revista de Terapia Ocupacional da Universidade de São Paulo, São Paulo, v. 23, n. 3, p. $237-$ 244, 2013. Disponível em: <http://www.revistas.usp.br/rto/ article/view/55816>. Acesso em: 15 jan. 2018.

MURASAKI, A. K.; GALHEIGO, S. M. Juventude, homossexualidade e diversidade: um estudo sobre o processo de sair do armário usando mapas corporais. Cadernos de Terapia Ocupacional da UFSCar, São Carlos, v. 24, n. 1, p. 53-68, 2016. http://dx.doi.org/10.4322/0104-4931. ctoAO0648.

PARKER, R. G. Abaixo do Equador: culturas do desejo, homossexualidade masculina e comunidade gay no Brasil. Rio de Janeiro: Record, 2002.

PERLONGHER, N. O. A prostituição Viril em São Paulo. São Paulo: Editora Brasiliense, 1987.

PRECIADO, B. Manifesto contrassexual: práticas subversivas de identidade sexual. São Paulo: N1 ediçôes, 2014.

SEDGWICK, E. K. A epistemologia do armário. Cadernos Pagu, Campinas, n. 28, p. 19-54, 2007. Disponível em: <http:// www.scielo.br/scielo.php?script $=$ sci_arttext\&pid $=$ S0104$83332007000100003 \& \operatorname{lng}=\mathrm{en} \& \mathrm{nrm}=\mathrm{iso}>$. Acesso em: 24 jan. 2018.

SIMÓES, J. A.; CARRARA, S. O campo de estudos socioantropológicos sobre diversidade sexual e de gênero no Brasil: ensaio sobre sujeitos, temas e abordagens. Cadernos Pagu, Campinas, n. 42, p. 75-98, 2014. http://dx.doi. org/10.1590/0104-8333201400420075.

SIMÓES, J. A.; FRANÇA, I. L. “Gueto ao mercado”. In: GREEN, J.N.; TRINDADE, R. Homossexualismo em São Paulo e outros escritos. São Paulo: Editora UNESP, 2005. p. 309-336. 
STRAW, W. Systems of articulation logics of change: communities and scenes in popular music. Cultural Studies, United States, v. 5, n. 3, p. 368-388, 1991. http://dx.doi. org/10.1080/09502389100490311.

STRAW, W. Cultural Scenes. Loisir et société/Society and Leisure, Canada, v. 27, n. 2, p. 411-422, 2004. https://doi. org/10.1080/07053436.2004.10707657.
TREVISAN, J. S. Devassos no paraíso: a homossexualidade no Brasil, da colônia à atualidade. Rio de Janeiro: Record, 2002 .

VEGA, A. P. Estilo e marcadores sociais da diferença em contexto urbano: uma análise da desconstrução de diferenças entre jovens em São Paulo. 2008. 135 f. Dissertação (Mestrado em Antropologia Social) - Universidade de São Paulo, São Paulo, 2008.

\section{Contribuição dos Autores}

Diego Eugênio Roquette Godoy Almeida realizou o trabalho de campo, descrição densa, análise dos dados e redaçáo do texto. Rosário Silvana Genta Lugli orientou e participou de todas as etapas, desde a concepção, execução, análise e redação dos resultados, aprovando seu conteúdo final. Todos os autores aprovaram a versão final do texto.

\section{Notas}

${ }^{1}$ Por convenção, as categorias analíticas ou êmicas estarão em itálico no texto, assim como os estrangeirismos.

2 Projeto aprovado pelo CEP Unifesp/HU/HSP: 1.727.514.

${ }^{3}$ Além de cena pop, outras expressões êmicas como rolê pop, galera do pop, as gays do pop são usadas com sentido semelhante.

4 “Ser da noite" é uma expressão êmica que nomeia todos os que exercem alguma atividade profissional nas festas. São os produtores, DJ's, performers, hostess, fotógrafos, divulgadores, drag queens. Eles formam uma rede social que se diferencia do público comum, com regras específicas de pertencimento e capital simbólico. Existe, além disso, importante tendência no público de seguir "carreira na noite", fato este associado ao menor constrangimento às expressóes de gênero não binárias.

${ }^{5}$ Considero não ser pertinente o uso das categorias “pedaço, mancha, circuito” propostas por Magnani (2012), já que estas não tratam dos conflitos, desvantagens e hierarquias que provocam continuidades e descontinuidades entre os territórios. 